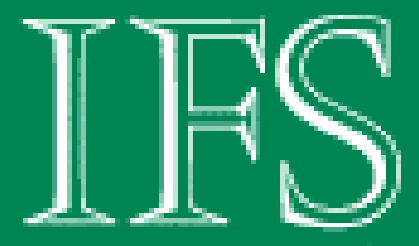

WAGES AND THE DEMAND FOR HEALTH: A LIFE CYCLE ANALYSIS

Christian Dustmann Frank Windmeijer 


\title{
Wages and the Demand for Health - A Life Cycle
}

\author{
Analysis* \\ Christian Dustmann ${ }^{\dagger} \quad$ Frank Windmeijer
}

June 2000

\begin{abstract}
This paper presents a life cycle model for the demand for health, and derives empirical specifications that distinguish between permanent and transitory wage responses. Using panel data, we estimate dynamic health and health input demand equations. We find evidence of negative transitory wage effects, and positive permanent effects. Estimation results based on our life cycle framework lead to very different conclusions than those based on static cross section analyses that are common in the literature. The analysis emphasises the importance to analyse health related behaviour in a dynamic life cycle context.
\end{abstract}

Key Words: Demand for Health, Life Cycle Models, Panel Data

JEL- Classification: C23, D91, I12

* We are grateful for comments on earlier drafts of the paper by Jerome Adda, Orazio Attanasio, Laura Blow, Richard Blundell, Axel Borsch-Supan, Hide Ichimura, Christian Herrera Salas, Costas Meghir, Ian Preston, Walter Ried, Jayne Taylor, and Adam Wagstaff. This study is part of the programme of research of the ESRC Center for the Microeconomic Analysis of Fiscal Policy at IFS. The financial support of the ESRC is gratefully acknowledged.

${ }^{\dagger}$ University College London, Department of Economics, Gower Street, London WC1E 6BT, Institute for Fiscal Studies, and IZA, Bonn.

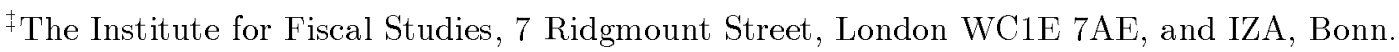




\section{Introduction}

Individual health and longevity are of rising public and political concern as both have important effects on public spending. Low health standards impose a heavy burden on welfare institutions. Many government interventions in Western countries are aimed at improving health levels. Across populations, we observe considerable variations in life expectancy and health status, which are largely explained by factors like wealth, technology, and the availability of medical services. On an individual level, genetic conditions may trigger illnesses, and impact on health and longevity. Much of the variation in health status as well as longevity between individuals is however due to the way resources are allocated to health enhancing measures. Conditional on genetic factors and other exogenous determinants, health as well as longevity are largely objects of individual choice.

To understand the links between individuals' socio-economic characteristics and their health status is an important pre-requisite for successful health related policies. To define target groups for government health programmes requires to understand which groups are most at risk. It is not surprising that much research effort has been devoted to establishing a link between individual specific characteristics, and health status as well as longevity. In this context, an interesting and important question is how individual health is related to the individuals' income. Although it is well understood that there is an association between income and health on an individual level, the precise nature of this relationship is not clear.

The theoretical foundations for understanding the demand for health in an intertemporal context have long been laid. An important first contribution to analysing the demand for health within a choice theoretical framework has been made by Grossman (1972a, 1972b). In his model, health can be augmented by health investments, which are generated by combining medical care services and time. Health serves two purposes. Firstly, it affects longevity. Secondly, it generates instantaneous benefits by enhancing productive time in every period, and by providing direct utility. Grossman's model 
has in subsequent years been extended in various directions. Recent contributions have, for instance, explored the implications of uncertainty for the optimal demand for health (e.g. Dardanoni and Wagstaff (1990), Seldon (1993), Picone, Uribe and Wilson (1998), and Liljas (1998)), or they have enhanced our understanding of the comparative dynamics of the model (e.g. Ried (1998, 1999), and Eisenring (1999)).

Grossman's (1972a) empirical formulation of his model produces demand functions which are determined by current period variables only if the instantaneous benefit of health is to enhance time (the investment model); they depend, in addition, on the marginal utility of wealth if the instantaneous benefit is to increase utility (the consumption model). Also, these demand functions can not be derived without assuming an instantaneous benefit of health.

Most empirical papers take Grossman's equations for the demand for health and health services as a starting point for econometric specifications (for instance, Cropper (1981), Muurinen (1982), Wagstaff (1985, 1993), Pohlmeier and Ulrich (1995), and Geil et al. (1997)). Nearly all these models relate current period health measures to current period variables only. ${ }^{1}$ The empirical health literature thus tends to neglect the implications of the intertemporal nature of the demand for health when estimating health demand functions. The empirical evidence these papers produce on the link between wages and individual health is not conclusive.

In a recent paper, Ehrlich and Chuma (1990) develop a version of the Grossman model in continuous time. Other than in Grossman's original work, in their model health investments are produced by combining goods and time using a technology which exhibits decreasing (as opposed to constant) returns to scale. They argue that a constant returns to scale technology introduces an indeterminacy with respect to the optimal health investment and health maintenance choices, and that no interior solution for the demand for health investments generally exists. ${ }^{2}$ While in Grossman's

\footnotetext{
${ }^{1}$ A notable exception is Wagstaff (1985), who estimates the consumption model, where health demand depends on the marginal utility of wealth.

${ }^{2}$ See Ried $(1998,1999)$ on this point, who argues that under certain conditions, the derived demand
} 
original work the demand for health is generated by its instantaneous benefit only, in Ehrlich and Chuma's version of Grossman's model, the demand for health is derived in conjunction with longevity and consumption choices. It depends on current period variables, as well as initial endowments, and is defined also if health creates no instantaneous benefit.

In this paper we assess the empirical implications of Ehrlich and Chuma's work. Based on their version of the Grossman model, we derive Frisch demand functions (see Browning, Deaton and Irish (1985)) for health and health inputs. These demand functions relate current period demands to current period variables, and to a parameter which links current period decisions with the entire future and history of the individual's optimisation problem (the relative marginal utility of health to wealth). This parameter is a sufficient statistic for all out of period information which affects current period demand. Frisch demand functions provide a natural way to distinguish between transitory and permanent demand responses.

In our empirical analysis, we estimate wage responses of the demand for health and health inputs. We distinguish between three parameters of interest. First, the response of an individual to wage changes along the individual's wage profile. Second, the difference in health (or health investments) between individuals due to a permanent wage difference. And third, the total difference in health (or health investments) between individuals with permanent wage differences. Within the model we develop, these parameters have a clear structural interpretation. They distinguish between wage responses over an individual's life cycle due to intertemporal substitution, and differences in health and health investments across individuals due to differences in permanent wages.

In contrast, straightforward regression analysis, as, for instance, suggested by Grossman's investment model, produces parameter estimates which have no clear interpretation within our life cycle framework. They are a mixture of evolutionary wage responses

for health inputs can be determined. 
along an individual's life cycle wage profile, and responses to wage differences across individuals. We demonstrate that these parameters may result in misleading conclusions.

We estimate demand for health capital equations, where we use as an approximation for health capital the (self-reported) state of health of individuals. We also estimate demand for health investment equations, where health investment is a combination of time and health services, which are bought in the market. We use as a measure for health investment whether the individual is involved in sporting activities. On both variables, we have repeated information on the same individual. The additional variation in demands within the same individual over time allows us to estimate short term wage responses.

In our model, individuals invest into health capital to delay death, which is endogenously determined. Furthermore, health capital may provide an instantaneous benefit by enhancing healthy time. We first assume that health capital provides no instantaneous benefits. In this case, differencing techniques can be used to identify evolutionary wage responses. In a second stage we impose structure on the shadow price of health capital, which allows us to identify permanent effects as well.

If health provides instantaneous benefits, estimators based on within-individual differencing do not identify the parameters of interest. We propose a simple test for instantaneous health benefits, and suggest an estimator which identifies evolutionary wage responses in this case. This is a matching type estimator, which compares individuals with the same predicted unobserved heterogeneity components.

Our results lend support to a dynamic model structure which distinguishes between permanent and temporary wage responses. We obtain negative evolutionary wage effects, and positive permanent effects. The implications for health related policies to be drawn from our specification are different, and may even lead to opposite conclusions, than those drawn from a model which neglects the inherent dynamic structure of the problem. 
The structure of the paper is as follows. In section 2, the equations for the demand for health services, health inputs and the stock of health are derived. Section 3 describes the data. Section 4 discusses the empirical estimation of these equations and presents the results of our empirical analysis. Section 5 concludes.

\section{The Model}

We follow Ehrlich and Chuma (1990) and develop a version of the Grossman model in continuous time, where the technology of health production exhibits diminishing returns (rather than constant returns, as in Grossman's model). We then derive the demand functions for health and health services.

Individuals maximize utility which is defined over consumption $c(t)$ and healthy time $h(t)$. They invest in health for two reasons: to delay death, which is endogenously determined, and to obtain an instantaneous benefit. This benefit is created by enhancing healthy time $h(t)$. Healthy time has three purposes: It is allocated to labour market activities, it increases utility, and it is invested into health production. Death occurs when the stock of health hits a critical minimum level. Healthy time at $t$ depends on the stock of health capital $H(t)$, which depreciates over the life cycle with an increasing rate $\sigma(t)$. Health capital is produced using time $m(t)$ and health services $M(t)$ as inputs.

The equation of change for health capital is given by

$$
\dot{H}(t)=I(t)-\sigma(t) H(t) ; \quad H(0)=H_{0}
$$

where $I(t)$ is investment in health capital, $\sigma(t)$ is the depreciation rate on health capital, with $\dot{\sigma}(t)>0$, and $H_{0}$ is the stock of health at $t=0$.

Investments in health capital, $I(t)$, are produced with a decreasing returns to scale technology, using goods (or health services) $M(t)$ and time $m(t)$. We assume the 
technology to be of a constant elasticity type:

$$
I(t)=\phi(t) M(t)^{a} m(t)^{b}
$$

where the parameters $a$ and $b$ denote the shares of $M(t)$ and $m(t)$ respectively, with $a+$ $b<1$. The good $M(t)$ summarises all inputs into the production of health capital which can be bought in the market place. The parameter $\phi(t)$ is a technology parameter.

The individual's time constraint is given by

$$
h(t)=m(t)+l(t)
$$

where $h(t)$ is healthy time, which is a concave function of the stock of health at time $t$. It is divided between time used to produce health capital, $m(t)$, and time devoted to the labor market, $l(t)$. Accordingly, health capital enhances the total time available for these two activities.

The cost minimizing demand function for services $M(t)$ is given by

$$
M(t)=\left[\frac{a}{b}\right]^{\frac{b}{a+b}} p_{M}^{-\frac{b}{a+b}} w(t)^{\frac{b}{a+b}} \phi(t)^{-\frac{1}{a+b}} I(t)^{\frac{1}{a+b}} .
$$

The resulting cost function is given by

$$
C(t)=\pi\left(w(t), p_{M}, \phi(t)\right) I(t)^{\frac{1}{a+b}}
$$

with unit cost $\pi$ :

$$
\pi\left(w(t), p_{M}, \phi\right)=B \phi(t)^{-\frac{1}{a+b}} p_{M}^{\frac{a}{a+b}} w(t)^{\frac{b}{a+b}} \quad ; \quad B=\left[\frac{a}{b}\right]^{\frac{b}{a+b}}+\left[\frac{a}{b}\right]^{-\frac{a}{a+b}}
$$

where $w(t)$ is the wage rate per unit of time, and $p_{M}$ is the price for inputs into health production. For simplicity, $p_{M}$ is assumed constant over time.

Using (3), (5), and (6), wealth develops according to the following equation of change:

$$
\dot{A}=r A(t)-\pi(t) I(t)^{\frac{1}{(a+b)}}-p_{c} c(t)+w(t) h(t) ; \quad A(0)=A_{0}
$$


where $r$ is a (time-constant) interest rate, and $A_{0}$ is the initial stock of wealth. Consumption in period $t$ is given by $c(t)$, with unit price $p_{c}{ }^{3}$

The individuals' utility function is given by

$$
\int_{0}^{T}[u(c(t))+v(h(t))] e^{-\rho t} d t
$$

where $u($.$) and v($.$) are strictly concave, and \rho$ is the rate of impatience.

Death occurs at time $T$, which is endogenously determined. The individual dies when the state of health hits a critical level $H^{C}$. At the end of life, the individual is assumed to leave no debts. The optimization problem is now to maximize (8) with respect to (1) and (7) and the following two end point restrictions:

$$
H(T)=H^{C}, \quad A(T) \geq \bar{A}
$$

where $\bar{A} \geq 0$ is the stock of wealth at $t=T$.

Denote the marginal utility of wealth and the marginal utility of health by $\lambda_{1}(t)$ and $\lambda_{2}(t)$ respectively. Then the Hamiltonian is given by

$$
\begin{aligned}
K= & {[u(c(t))+v(h(t))] e^{-\rho t} } \\
& +\lambda_{1}(t)\left[r A(t)-\pi I(t)^{\frac{1}{(a+b)}}-p_{c} c(t)+w(t) h(t)\right] \\
& +\lambda_{2}(t)[I(t)-\sigma(t) H(t)] .
\end{aligned}
$$

This is a free endpoint optimal control problem, which can be solved using Pontryagin's maximum principle. Individuals choose consumption and investment into health production, where investment is a combination of time and health services. These optimal choices determine the path of capital and health capital.

\footnotetext{
${ }^{3}$ Other than in Grossman's model, where $c(t)$ is also produced inside the household, we assume for simplicity that consumption goods are purchased directly in the market place.
} 


\subsection{The Demand for Health, Health Services and Health In- vestment}

We derive the demand for health services $M(t)$ and health investment $I(t)$ in appendix A. Taking logs of equation (39) in the appendix gives the (log) demand equation for health services $M(t)$ :

$$
\ln M(t)=\beta_{0}+\beta_{1} \ln \phi(t)-\beta_{2} \ln p_{M}-\beta_{3} \ln w(t)+\beta_{4} \ln \eta(t),
$$

where the $\beta$ 's are functions of $a$ and $b$, and $\eta(t)=\lambda_{2}(t) / \lambda_{1}(t)$ is the relative shadow value of health capital.

The demand for health investment equation is given by (38) in the appendix. Taking logs leads to

$$
\ln I(t)=\delta_{0}+\delta_{1} \ln \phi(t)-\delta_{2} \ln p_{M}-\delta_{3} \ln w(t)+\delta_{4} \ln \eta(t)
$$

where the $\delta$ 's are functions of $a$ and $b$.

Demand equations like (11) and (12) are Frisch demand functions; they depend on the parameter $\eta(t)$, the relative shadow value (or relative marginal utility) of health. For our model, $\eta(t)$ is given by ${ }^{4}$

$$
\eta(t)=\eta(0) e^{\int_{0}^{t}[\sigma(\tau)+r] d \tau}-E(t)-F(t)
$$

where

$$
\begin{gathered}
E(t)=\int_{0}^{t} w(\tau) h^{\prime}(\tau) e^{\int_{\tau}^{t}[\sigma(s)+r] d s} d \tau, \\
F(t)=\int_{0}^{t} h^{\prime}(\tau) v_{h} e^{(r-\rho) \tau} \frac{1}{\lambda_{1}(0)} e^{\int_{\tau}^{t}[\sigma(s)+r] d s} d \tau,
\end{gathered}
$$

and $h^{\prime}$ is the derivative of healthy time $h(t)$ with respect to the stock of health capital, $H(t)$. The parameter $\lambda_{1}(0)$ is the shadow value (or marginal utility) of wealth at $t=0$; the parameter $\eta(0)$ is the shadow value of health, relative to the shadow value of wealth, at time 0 .

\footnotetext{
${ }^{4}$ Equation (13) is obtained by solving equation (34) in the appendix.
} 
The term $E(t)$ reflects the instantaneous benefit of health by enhancing time which may be allocated to the marketplace. The term $F(t)$ captures the instantaneous benefit of healthy time by increasing contemporaneous utility levels. If health is beneficial only to delaying death, total time available does not depend on the period stock of health capital. In this case, $h(H(t))=h$, where $h$ is constant, and the shadow value of health reduces to

$$
\eta(t)=\eta(0) e^{\int_{0}^{t}[\sigma(\tau)+r] d \tau}
$$

Notice that the assumption of instantaneous health benefits affects the demand equations (11) and (12) only via $\eta(t)$.

\subsection{Permanent and Evolutionary Wage Responses}

Consider now the effect of wage changes on the demands for $I(t)$ and $M(t)$, and let $\eta(t)$ be given by (14). The parameter $\eta(0)$ summarises all relevant information from other periods; it links the demand for $M(t)$ or $I(t)$ in the current period to all historic and future values of the model variables. It is therefore a sufficient statistic for all outside period information which affects the current period demand. In a world of perfect certainty, any changes in wages do not affect $\eta(0)$, since they are fully anticipated by the individual. The effect of a change in current wages is a response along an individual's wage profile, and is sometimes referred to as response to evolutionary wage changes (see MaCurdy (1981), Blundell and MaCurdy (1999)). The elasticity of health service demand or health investment with respect to evolutionary wage changes is an intertemporal substitution elasticity. The wage response conditional on $\eta(t)$ reflects that time allocated to the labour market competes with time invested into health production. It is negative for both demands, implying that demands for services and inputs are lower when wages are high.

The effect on demands via $\eta(0)$ is determined by the three equilibrium conditions for

$\eta(0)$, the marginal utility of wealth $\lambda_{1}(0)$, and the optimal longevity $T$ (see equations (35) -(37) in the appendix). This effect is a permanent wage effect, in the sense that 
it shifts the entire life cycle profile of demand. It measures permanent differences in demands across individuals.

Consider the health investment equation (12). With respect to wage responses, there are three parameters of interest. The first is the evolutionary response of health investments to changes in wages. This parameter answers the question to which extent individuals change their health investments when wages change along their wage profile, as a consequence of substituting time away from health enhancing activities to the workplace. This is the effect of changes in wages, conditional on $\eta(0)$.

The second is the difference in health investments between individuals due to a permanent difference in their wages, induced solely by differences in $\eta(0)$ (remember that $\eta(0)$ is a function of the entire future and history of wages). This parameter answers the question to what extent a permanent difference in wages between individuals contributes to a shift in the investment profile.

The third is a combination of the first and the second. It answers the question to which extent a permanent difference in wages between two individuals is associated with differences in health investments, being due to both permanent differences in the investment profile, and evolutionary responses along an individual's profile.

All three parameters are important for health related policies. None can be identified by simple cross section regression analysis, as done in most of the empirical literature. Empirical results from a model which relies on straightforward regression analysis, using across-individual variation only to identify wage responses, yields a mixture of evolutionary and permanent wage responses.

We have illustrated this in figure 1 , where the vertical axis carries time, and the horizontal axis to the left of the time axis carries health investments $I(t)$, and to the right of the time axis wages $w(t)$. We consider two individuals, $A$ and $B$, with the same initial wages. Individual $A$ has a steeper wage profile than individual $B$, and therefore a higher life cycle wage income. To simplify the exposition, consider a stylised version of (12), which describes the relationship between health investments of individual $J$, 


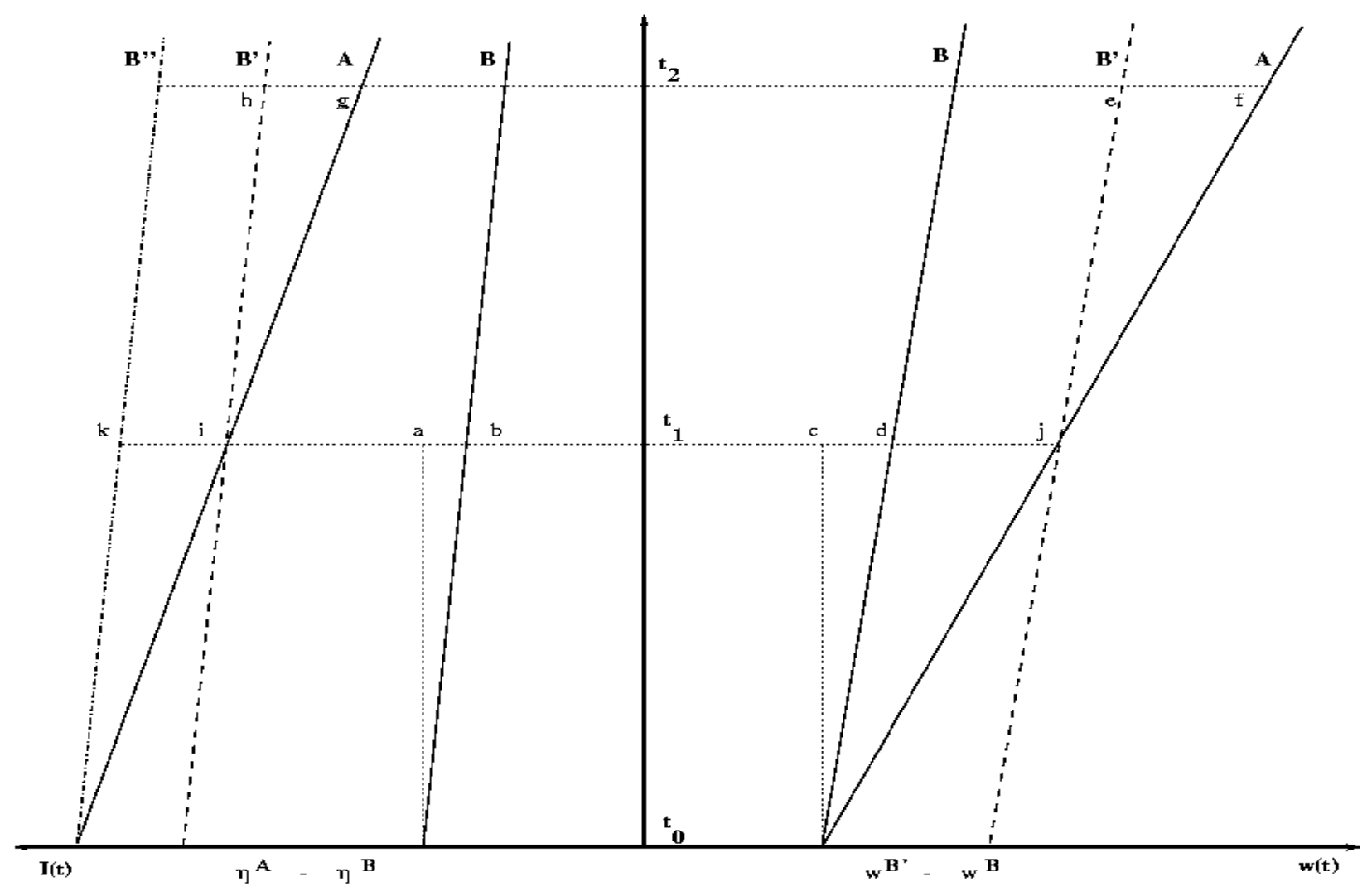

Figure 1: Evolutionary and Permanent Wage Responses 
wages and the parameter $\eta$ :

$$
I^{J}(t)=a_{0}+a_{1} w^{J}(t)+\eta^{J}, \quad J=A, B, \quad \text { where } \quad a_{1}<0 .
$$

The parameter $\eta$ is an increasing function of the entire wage profile of the individual. Accordingly, $\eta^{A}>\eta^{B}$, and health investments are on a higher profile for individual $A$. At $t_{0}$, wages for the two indviduals are the same, and the difference in health investments is due to differences in $\eta$ only: $I^{A}\left(t_{0}\right)-I^{B}\left(t_{0}\right)=\eta^{A}-\eta^{B}$.

In our simple graphical representation, the evolutionary wage effect is given by the ratio of health investments to wages at two points along an individual's wage and health investment profiles. There are at least two possibilities to identify this parameter. First, by using variations within individuals only. For example, choosing periods $t_{0}$ and $t_{1}$, the evolutionary wage effect is given by $a_{1}=\left(I^{B}\left(t_{1}\right)-I^{B}\left(t_{0}\right)\right) /\left(w^{B}\left(t_{1}\right)-w^{B}\left(t_{0}\right)\right)$ (corresponding to $(b-a) /(d-c)$ in the figure), which is negative. Second, by matching individuals with different life cycle wage paths, but with the same $\eta$. To illustrate this, we have drawn the individual $B^{\prime}$, which has the same wage path as $B$, but at a level such that $\eta^{B^{\prime}}=\eta^{A}$. If we now choose any time $t$ (say $t_{2}$ ), then $a_{1}$ is equal to $\left(I^{A}\left(t_{2}\right)-I^{B^{\prime}}\left(t_{2}\right)\right) /\left(w^{A}\left(t_{2}\right)-w^{B^{\prime}}\left(t_{2}\right)\right)$ (corresponding to $\left.(g-h) /(f-e)\right)$.

The permanent difference in health investments between $A$ and $B$ due to permanent differences in their wages is equal to $I^{A}\left(t_{0}\right)-I^{B}\left(t_{0}\right)$. This is equal to $\eta^{A}-\eta^{B}$, and it corresponds to the difference in health investments at a point where wages for the two individuals are equal. The second parameter of interest is this difference, relative to the difference in permanent wages. We have drawn the wage path of individual $B^{\prime}$, which we obtain by shifting $B$ to the right, so that the life cycle wage for $A$ and $B^{\prime}$ are equal. Accordingly, $\eta^{B^{\prime}}=\eta^{A}$. Then the permanent wage difference is equal to $w^{B^{\prime}}-w^{B}$, and the parameter of interest is $\left(\eta^{A}-\eta^{B}\right) /\left(w^{B^{\prime}}-w^{B}\right)$.

Finally, the third parameter of interest is the total effect of a permanent change in wages on health investments between two individuals. Consider again shifting $B$ 's profile to $B^{\prime}$. We have also drawn the corresponding investment profile, which is also 
labeled by $B^{\prime}$. The total effect on health investments of this shift is the combined permanent and evolutionary response, which is given by

$$
\frac{I^{B^{\prime}}-I^{B}}{w^{B^{\prime}}-w^{B}}=\frac{\eta^{B^{\prime}}-\eta^{B}}{w^{B^{\prime}}-w^{B}}+a_{1}
$$

In the figure, this corresponds to $(k-b) /(j-d)+(i-k) /(j-d)$.

Now suppose we estimated the above relationship by straightforward regression, using a cross section of individuals. Suppose further we observe both $A$ and $B$ in $t_{2}$. Then the parameter we obtain is equal to

$$
\frac{I^{A}\left(t_{2}\right)-I^{B}\left(t_{2}\right)}{w^{A}\left(t_{2}\right)-w^{B}\left(t_{2}\right)}=\frac{\eta^{A}-\eta^{B}}{w^{A}\left(t_{2}\right)-w^{B}\left(t_{2}\right)}+a_{1} .
$$

This parameter is a compound effect of the (negative) evolutionary wage response, and a term which involves differences in the permanent response, normalised by differences in wages in the observation period. For the way we have drawn the diagram, this compound effect is positive. ${ }^{5}$ This estimated parameter does not correspond to any of the parameters of interest. It is different for any $t$ we choose; in applications, it depends on the distribution of the sample.

It may give misleading answers to questions like "Should individuals with low wages be targeted by government programmes to enhance health standards". Suppose that the estimated parameter from a simple cross section estimation is positive. Then this may wrongly be interpreted as individuals with higher wages invest more into health. But temporarily poor people may well invest more into health than temporarily rich people, if their total life cycle income is higher. In our figure, individuals $A$ and $B$ have the same wages in $t_{0}$; nevertheless, investments of $A$ are higher than investments of $B$, because $A^{\prime} s$ life cycle income is higher. Cross section results would identify both individuals as equally eligible for any support programme.

Over an individual's life cycle wage path, however, a large transitory increase in wages may lead to a strong reduction in health investments, because individuals may

\footnotetext{
${ }^{5}$ This is also the case for our applications below.
} 
substitute away time from health enhancing activities. Individuals with high wages may therefore suffer from serious illness as a result of a temporary neglect of their health. That health hazards induced by temporary neglect of health of high wage individuals can be severe is well documented in the medical literature. ${ }^{6}$ Again, cross section results would fail to identify these individuals as individuals who are at risk.

In our figure, for instance, the distance in health investments between $A$ and $B$ narrows, while the contemporaneous wage differential increases. This is due to $A$ experiencing a higher wage growth than $B$, and thus substituting time away from health investment to the market place. A simple cross section analysis would identify $A$ and $B$ as investing equally in health at $t_{0}$, whereas at $t_{0}$ we observe the largest difference in health investment between the two; it would also suggest that the difference between $A$ and $B$ is largest in $t_{2}$, whereas it is smallest (and it could even be negative if the response of health investments to evolutionary changes in wages is sufficiently large).

The discussion shows the importance of distinguishing between evolutionary and permanent wage responses. In section 4, we estimate demand for health investment equations and demand for health equations, distinguishing between evolutionary wage responses, and permanent wage responses. To identify these two effects, we use data from a long panel, which we describe in the next section.

\section{The Data}

The data we use are from the German Socio Economic Panel (GSOEP), and cover the period between 1984 and 1995. We select a sample of working males, between 25 and 60 years of age. The sample is unbalanced, allowing for attrition from the survey, as well as for new entrants to the sample.

As a measure for the stock of health, we use a self-reported measure of contentment

\footnotetext{
${ }^{6}$ For example, Marmot et al. (1997) show that, after controlling for working conditions, it is those in the highest social/occupational grade that have the highest incidence of stress related illness.
} 
with health, which is reported in all 12 years on an eleven point scale. Self assessed health status has been found in many studies to be a useful measure in assessing the overall health of an individual, see for example Wannamethee and Shaper (1991) and references therein. ${ }^{7}$ We rescale this measure to be bound between 0 and 1 . As a measure for investment into health we use information on whether the individual performs some kind of sporting activity on a weekly basis. Sporting activities are clearly a combination of health input goods $M(t)$ and time $m(t)$, and contribute to increasing the stock of health capital. The medical literature has established a clear link between physical fitness, and longevity. ${ }^{8}$ Information on this investment measure is available in 5 out of the 12 years of data. We recode this measure into a binary variable, where 1 indicates that the individual pursues sports activities at least once a week. The wording of the questions in the questionnaire is given in appendix B, and Table 1 reports the frequencies of occurrence and summary statistics.

As a measure for wages we use hourly wages measured in 1984 DM. In all 12 years of the survey we observe monthly gross earnings, as well as hours worked, hours worked overtime, and whether overtime is paid for. The wage variable is constructed by dividing monthly earnings by the number of paid hours worked per month. Summary statistics are reported in Table 1.

\footnotetext{
${ }^{7}$ Wannamethee and Shaper (1991) assess the health status of middle-aged British men, using a number of objective medical measures. They also ask individuals for their subjectively perceived health status. Comparing these measures, they conclude that (p. 245) "The results of this study strongly suggest that a simple question on perceived health status is a useful indicator of health status in middle-aged men and appears to reflect their current health status".

${ }^{8}$ For instance, Lee, Blair and Jackson (1999) investigate 22000 males aged between 30 and 83 over an 8 year period. They found that physical fitness, conditional on body weight, is significantly and positively associated with longevity.
} 
Table 1: Summary Statistics

\begin{tabular}{l|c|c|c}
\hline \hline Variable & Health & Health Investment & Log Wages \\
\hline Acronym & $H D$ & $I D$ & $\ln w$ \\
\hline Definition & $\begin{array}{c}\text { Contentment } \\
\text { with health }\end{array}$ & $\begin{array}{c}\text { Doing sports at } \\
\text { least once a week }\end{array}$ & $\begin{array}{c}\text { Log Real } \\
\text { Hourly Wage }\end{array}$ \\
\hline Range & $0,0.1, \ldots, 1$ & 0,1 & \\
& $1=$ very content & & \\
Years available & $84-95$ & $85,86,88,92,94$ & $84-95$ \\
$\#$ individuals & 3324 & 2791 & 3324 \\
$\#$ observations & 19100 & 7818 & 19100 \\
& & & 3.0123 \\
mean & 0.7056 & 0.3058 & 0.3606 \\
std dev & 0.2083 & 0.4608 & 0.1681 \\
within std dev & 0.1369 & 0.2542 & 0.3529 \\
between std dev & 0.1762 & 0.4041 & \\
\hline \hline
\end{tabular}

Figures 2 to 5 present graphical information of some of the variables we use in our analysis. In figure 2, the age distribution in the sample is displayed. The highest frequency is at age 29, the lowest at age 60 . Figure 3 presents the average log real wage by age. Wages rise substantially between age 25 and 44 , level out, and slightly decline after age 48 .

The mean for our measure for the stock of health at different ages is depicted in figure 4. It declines steadily with age, from an average value of 0.77 at age 25 , to a low of 0.61 at age 59 . 


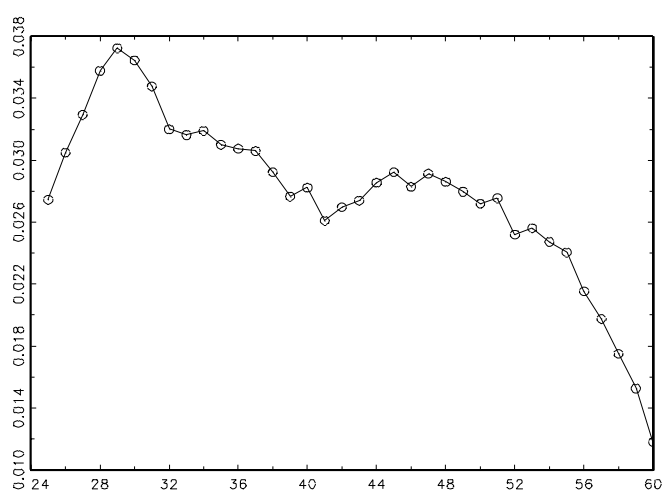

Figure 2: Sample frequency by age

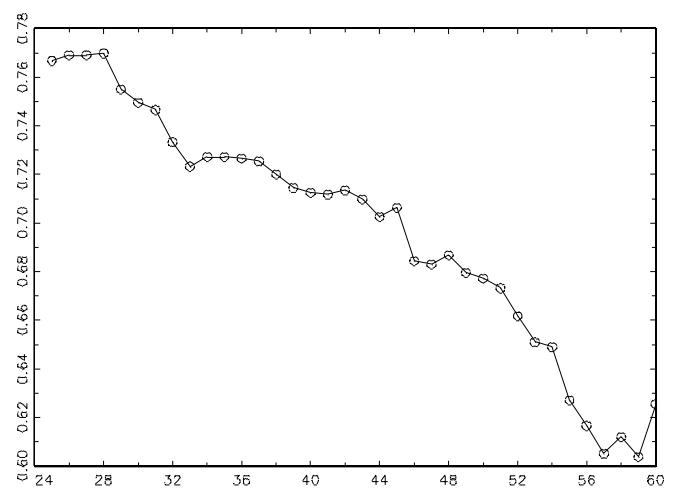

Figure 4: Average of $H D$ by age

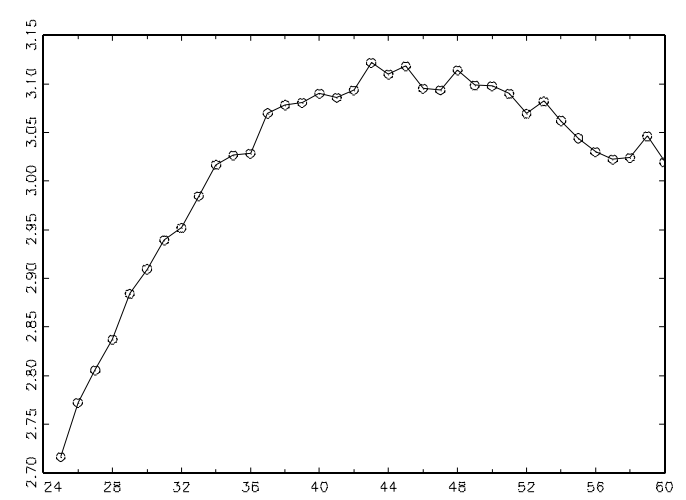

Figure 3: Average of log real wage by age

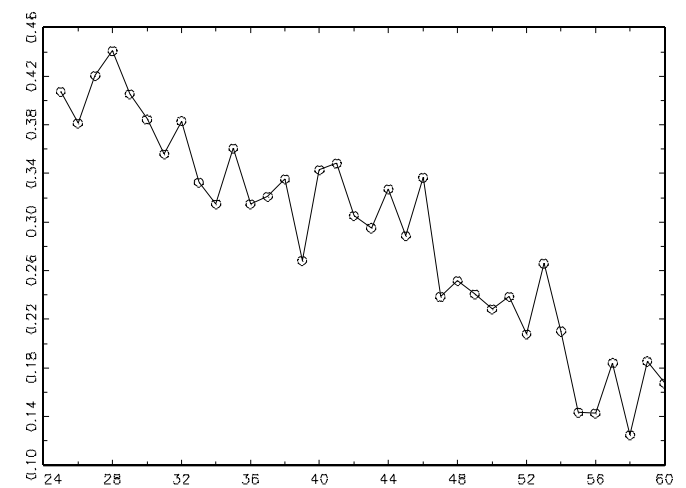

Figure 5: Average of $I D$ by age

The respective pattern for sport activities is depicted in figure 5. It also declines, with $44 \%$ of the sample participating at age 28 , whereas only $12 \%$ do sports on a weekly basis at age 58. This is not compatible with what we should expect on the grounds of our theoretical model, where investments into health should counteract an increasing depreciation of the stock of health capital. It suggests that this measure is only proxying one component of investment, and may be substituted by other components later in life. It may also suggest cohort effects: doing sports may be a way of improving health which is related to the individual's cohort.

To distinguish between age and cohort effects, we have plotted the mean of the health and sport variables over the 12 years period for different cohorts, where we define the cohort by the age of the individual in 1984 (figures 6 and 7). Figure 6 shows 
that within cohorts, the measure for the stock of health clearly declines with age; there are some slight level differences between the various cohorts. Figure 7 illustrates the same for the sport activity variable. It shows that within cohorts, the demand for sports is quite volatile, and no clear pattern is visible. Demand for sports is lower the older the cohort, which has contributed to generating the downward trend in figure 5 .
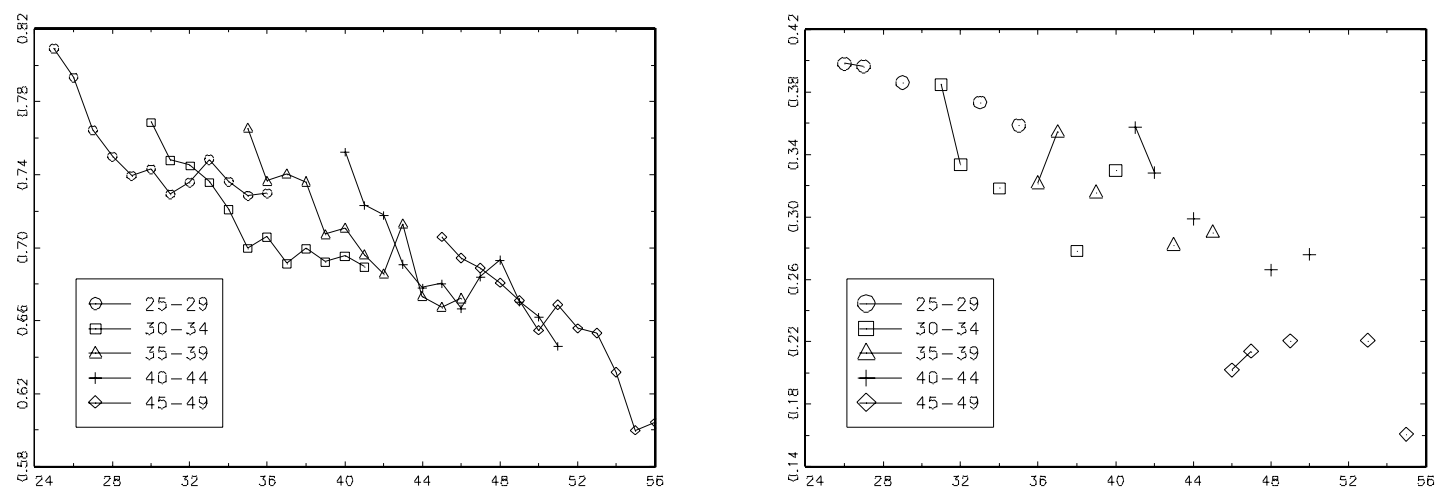

Figure 6: Average of $H D$ by 1984 age cohort Figure 7: Average of $I D$ by 1984 age cohort

The figures indicate that the sport variable is capturing only some components of health investments, and it is related to cohort, and age; it may also be related to occupational characteristics. In our estimations, we difference out all time constant characteristics; furthermore, we condition on age and time, which should account for the cohort effects visible in the figures. The remaining signal in this variable should be a good proxy for health investments.

In figure 8 , we have plotted the lifetime health paths for quartiles of the household income distribution, computed as the average household income over the entire observation period. This should be a rough approximation of permanent income. The profiles decline with age, and are clearly higher for the higher income quartiles. This indicates a higher health path for individuals with higher permanent income. Figure 9 illustrates this pattern for the sports variable; again, a wealth effect is clearly visible. 

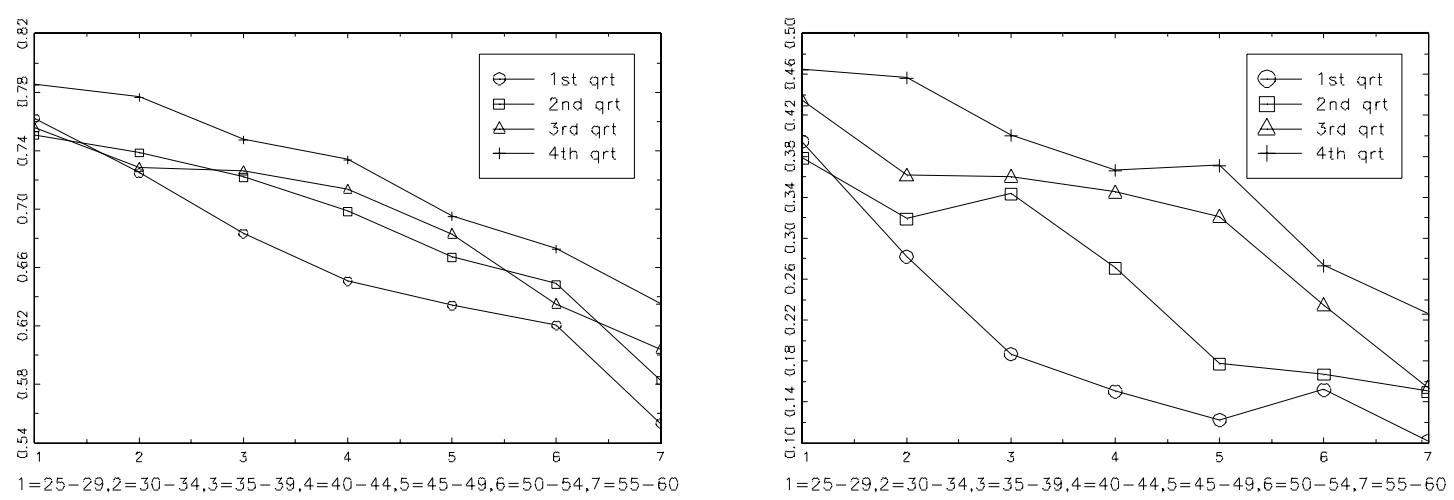

Figures 8 and 9: Average of $H D$ and $I D$ by mean $H H$ income quartile for 7 age groups

\section{Empirical Analysis}

We estimate a demand equation for health investment, $I(t)$, and for the health stock, $H(t)$. Our empirical specifications are based on models (12) and (1). The demand for health investment equation is already in a log-linear form. The health stock equation is a dynamic equation, and we consider its discrete counterpart:

$$
\begin{aligned}
H(t)= & (1-\sigma) H(t-1) \\
& +\exp \left(\delta_{0}+\delta_{1} \ln \phi(t-1)-\delta_{2} \ln p_{M}-\delta_{3} \ln w(t-1)+\delta_{4} \ln \eta(t-1)\right),
\end{aligned}
$$

where we have substituted the expression for $I(t-1)$ in (12). Alternatively, it follows from (1) that the log of the stock of health capital at $t$ can be written as $\ln H(t)=$ $\ln I(t)-\ln \sigma(t)-\ln (1+\widetilde{H} / \sigma(t))$, where $\widetilde{H}=\dot{H} / H$ is the relative change in health capital. If one is willing to assume that $\widetilde{H} / \sigma(t)=0$, then one obtains (using (12)):

$$
\ln H(t)=\xi_{0}+\xi_{1} \ln \phi(t)-\xi_{2} \ln p_{M}-\xi_{3} \ln w(t)+\xi_{4} \ln \eta(t)-\ln \sigma(t)
$$

The assumption that $\widetilde{H} / \sigma(t)=0$ implies that investment into health capital exactly offsets depreciation. Over large parts of the life cycle, this assumption may not be unreasonable. Furthermore, when estimating a differenced version of (16), we only require $\widetilde{H} / \sigma(t)$ to be constant between two periods. Accordingly, equation (16) may 
be a good starting point for an empirical model. We estimate both the dynamic model in (15), and its simpler version in (16).

Our first estimation strategy is to estimate a model where health has no instantaneous benefit, which results in an expression for $\eta(t)$ as in (14). Notice that the two important mechanisms by which wages affect $H(t)$ and $I(t)$ are present in this model: a direct (negative) effect by substituting time away from production of health to the marketplace, and an indirect and permanent effect by shifting the entire health profile of the individual. We estimate the evolutionary wage effect by differencing out the term $\eta(0)$. We then estimate permanent wage effects, where we approximate $\eta(0)$ as a function of initial health, initial wealth, and individual lifetime wage profiles.

We test this version of the model against models where health has an instantaneous benefit. The idea of our testing procedure is that in the latter case, differencing of $\ln \eta(t)$ leads to an equation with an error term which still contains a function of $\eta(0)$ (and, if healthy time enters the utility function, of $\lambda_{1}(0)$, see (13)), and the lifetime path of wages up to time $t$. This term should then be correlated with past wages and other variables which affect $\eta(0)$, which is testable. Our test results indicate that the restricted version of the model can not be rejected against a model with instantaneous health benefits.

If instantaneous health benefits were present, the parameter $\eta(t)$ would be given by equation (13). An estimation strategy which can identify evolutionary wage responses in this case is a matching type estimator, which differences across individuals with the same $\eta(t)$. Matching is done on a function of life-cycle wages, life-cycle wealth, initial wealth and health, age, and education. To ensure the robustness of our estimates, we report results of this estimator as well.

\subsection{No instantaneous health benefits}

If there are no instantaneous health benefits, $\eta(t)$ is given by (14). Define the variable $Y_{i t}$, which corresponds to $I_{i t}$ or $H_{i t}$ in equations (12) and (16), where $i=1, \ldots, N$ is the 
index for individuals and $t=1, \ldots, T$ is the time index. Furthermore, summarise variables which determine the demand in the vector $X$, and the corresponding parameters in $\delta$. Then the generic empirical model for equations (12) and (16) is given by

$$
\ln Y_{i t}=X_{i t}^{\prime} \delta+\zeta \ln w_{i t}+\ln \eta_{i}^{0}+v_{i t} .
$$

If repeated information on the same individual is available, estimation of equation (17) after taking first differences is straightforward. Denote the difference operator between period $t$ and $t-1$ by $\Delta$, then

$$
\Delta \ln Y_{i t}=\Delta X_{i t}^{\prime} \delta+\zeta \Delta \ln w_{i t}+\Delta v_{i t}
$$

The vector $X_{i t}$ includes $(\log )$ prices, the rates of interest and depreciation, the rate of decay of health capital, the technology parameter, and other time constant variables which affect the demand for health and health investment. We assume the log of the rate of depreciation $\sigma(t)$ to be quadratic in age. Furthermore, any changes in prices or the technology parameter should be picked up by time dummies, and by age effects. ${ }^{9}$ Accordingly, in our empirical specification, $\Delta X_{i t}=\left[\delta_{0 t}, \Delta a g e_{i t}^{2}\right]$, where the $\delta_{0 t}$ are time effects.

The dependent variables in equations (17) and (18) are $\ln H$ and $\ln I$. These variables are unobservable and we use as proxy variables the self-reported health index, $H D$, and the binary indicator for doing sports at least once a week, $I D$, respectively. It is natural to assume that there exists the following mapping from $\ln H$ to $H D$

$$
H D=j \text { if } c_{j-1}<\ln H<c_{j}
$$

\footnotetext{
${ }^{9}$ In Germany, medical services are financed by contributions to a compulsory insurance scheme. Contributions are in the form of a payroll tax, income dependent, and financed to equal parts by the employed and the employee. This scheme finances services also for the non-employed family members of the contributing individual. The scheme covers about 90 percent of the German population (see Pohlmeier and Ulrich, 1995, for details). Accordingly, there is little heterogeneity in the price of medical care due to differences in insurance schemes, as, for instance, in the US.
} 
for $j=0,0.1, \ldots, 1$, and where the $c_{j}$ are threshold parameters. As $I D$ is a simple binary indicator the postulated relationship between $\ln I$ and $I D$ is

$$
I D=1 \text { if } \ln I>c .
$$

It is common practice to estimate the parameters in these models by (ordered) probit estimation techniques. Estimating (ordered) probit models with fixed effects and weakly exogenous variables (see the discussion below) is difficult. We therefore estimate linear models with the indices $H D$ and $I D$ as the dependent variables. Under some general assumptions on the data generating process, these linear models will estimate the parameters up to scale. ${ }^{10}$

Because of the scaling of the parameters, as in all models with discrete dependent variables, interpretation of the size of the coefficients is problematic. In a linear model, not only does the standard deviation of the error term scale the parameters. The varying width of the intervals between the thresholds further scales the coefficients, as it is unlikely that the distance for an individual between a reported 2 and 3 is the same as the distance between 7 and 8 . We therefore refrain from any direct interpretation of the size of the coefficients. However, we can assess the relative magnitude of permanent and evolutionary wage responses.

Define the variable $Y D_{i t}$ which corresponds to $I D_{i t}$ or $H D_{i t}$, then the empirical model in first differences is specified as ${ }^{11}$

$$
\Delta Y D_{i t}=\Delta X_{i t}^{\prime} \delta^{*}+\zeta^{*} \Delta \ln w_{i t}+\Delta u_{i t}
$$

At the level of empirical implementation, we allow for possible feedback mechanisms of health on wages. Notice that, as in all surveys, the wage at the time of the interview is likely to be set at an earlier date. Therefore, current observed wages are not contemporaneously correlated with health shocks. However, wages at interview time may be

\footnotetext{
${ }^{10}$ See Chung and Goldberger (1984), Ruud (1986) and Newey (1986).

${ }^{11}$ In the remainder, we drop the ${ }^{*}$ superscripts when we present estimation results.
} 
correlated with past health status, and, accordingly, with $u_{i t-s}, s>0$. Hence, estimating the parameters in model (19) by OLS will result in biased coefficient estimates. ${ }^{12}$ We use an instrumental variable Generalised Methods of Moments (GMM) estimator, instrumenting the current wage difference by lagged levels of wages. ${ }^{13}$ The full instrument set used in the estimation is

$$
z_{i t}=\left[1, \ln w_{i t-1}, \ln w_{i t-2}, \ln w_{i t-3}, a g e_{i t}, a g e_{i t}^{2}, e d u c_{i}, e d u c_{i}^{2}, e d u c_{i} \times a g e_{i t}\right],
$$

where $e d u c_{i}$ is the years of schooling of individual $i{ }^{14}$ The age variable is rescaled to be 0 at age 25 .

The estimation results are presented in Table 2. The parameter $\bar{\delta}_{0 t}$ is the mean of the time dummies. This parameter is interpretable as the combined effect of the linear age term, and cohort effects. It is negative for the health equation, reflecting a constant deterioration in the stock of health over the life cycle, as indicated in figure 3. It is also negative for the sports equation, which could be due to the cohort effect we have pointed out above. For both the health and health investment equations the response to evolutionary wage changes is negative. This is compatible with a negative intertemporal substitution elasticity, as predicted by our model. Both effects, however, are not estimated very precisely.

\footnotetext{
${ }^{12}$ For the same reason, a within groups estimator can not be used here.

${ }^{13}$ Let $Z_{i}$ be a matrix of instruments, and $u_{i}$ be a vector of prediction errors. The GMM estimator minimises $\left(\frac{1}{N} \sum_{i} Z_{i}^{\prime} u_{i}\right)^{\prime} W_{N}\left(\frac{1}{N} \sum_{i} Z_{i}^{\prime} u_{i}\right)$, where $W_{N}$ is a weight matrix. Given consistent estimates using an initial weight matrix, with residuals $\widetilde{u}_{i}$, the efficient two-step GMM estimator uses $\left(W_{N}=\frac{1}{N} \sum_{i} Z_{i}^{\prime} \widetilde{u}_{i} \widetilde{u}_{i}^{\prime} Z_{i}\right)^{-1}$. See Hansen (1982).

${ }^{14}$ The instrument set for an individual over time is given by

$$
Z_{i}=\left[\begin{array}{cccc}
z_{i 1} & 0 & 0 & 0 \\
0 & z_{i 2} & 0 & 0 \\
0 & 0 & \ddots & 0 \\
0 & 0 & 0 & z_{i T-1}
\end{array}\right]
$$

The parameters are estimated by GMM using the program DPD98 for Gauss, Arellano and Bond (1998).
} 
Table 2. Estimation results for first-differenced models

\begin{tabular}{|c|c|c|c|c|c|}
\hline \multirow{3}{*}{ Dependent variable } & \multicolumn{2}{|c|}{ Health } & \multicolumn{2}{|c|}{ Health Investment } & \\
\hline & \multicolumn{2}{|c|}{$H D$} & \multicolumn{2}{|c|}{$I D$} & \\
\hline & coeff & std err & coeff & std err & \\
\hline$\overline{\delta_{0 t}}$ & -0.0090 & 0.0015 & -0.0119 & 0.0040 & \\
\hline$a g e^{2} / 100$ & -0.0041 & 0.0044 & 0.0084 & 0.0108 & \\
\hline $\ln w$ & -0.0163 & 0.0187 & -0.0308 & 0.0680 & \\
\hline Sargan (p-value) & 74.32 & $(0.741)$ & 12.44 & $(0.992)$ & \\
\hline \# of individuals & 26 & & & & \\
\hline \# of observations & 139 & & & & \\
\hline \multicolumn{6}{|c|}{ Efficient two-step GMM results. } \\
\hline \multicolumn{6}{|c|}{ Standard errors are robust to heteroscedasticity and correlation over time. } \\
\hline \multicolumn{6}{|c|}{$\overline{\delta_{0 t}}$ is the mean of the time effects, weighted for unequal period lengths } \\
\hline \multicolumn{6}{|c|}{ in the health investment equation. } \\
\hline The Sargan test is a & test for ir & strume & validity. & & \\
\hline
\end{tabular}

We now turn to the dynamic health stock equation in (15), which can be written as:

$$
\begin{aligned}
H_{i t} & =\alpha H_{i t-1}+I_{i t-1} \\
& =\alpha H_{i t-1}+\exp \left(X_{i t-1}^{\prime} \delta+\zeta \ln w_{i t-1}\right) \eta_{i}^{0} v_{i t}
\end{aligned}
$$

where $\alpha=(1-\sigma)$, and $v_{i t}$ is an idiosyncratic (multiplicative) error term. Notice that the dynamic model is multiplicative in $\eta_{i}^{0}$, so that straightforward differencing is not feasible. We can however quasi-difference the model to eliminate the fixed effect. The quasi-differenced equation is given by: $:^{15}$

${ }^{15}$ See Chamberlain (1992), Wooldridge (1997) and Blundell, Griffith and Windmeijer (1999). 


$$
\begin{aligned}
& \left(H_{i t}-\alpha H_{i t-1}\right) \exp \left(-\left(\Delta X_{i t-1}^{\prime} \delta+\zeta \Delta \ln w_{i t-1}\right)\right)-\left(H_{i t-1}-\alpha H_{i t-2}\right) \\
= & v_{i t} \exp \left(-\left(\Delta X_{i t-1}^{\prime} \delta+\zeta \Delta \ln w_{i t-1}\right)\right)-v_{i t-1}
\end{aligned}
$$

where the error term on the right hand side has zero mean, conditional on appropriate instruments. As $H$ is unobserved, we estimate the model using $e^{H D}$ to approximate $H$. Again, this implies that the parameters $\delta$ and $\zeta$ are estimated up to scale. The parameters of the model can be estimated by GMM, where we use as instruments the variables $^{16}$

$$
\begin{aligned}
z_{i t}= & {\left[1, e^{H D_{i t-3}}, e^{H D_{i t-4}}, e^{H D_{i t-5}}, \ln w_{i t-1}, \ln w_{i t-2}, \ln w_{i t-3}, a g e_{i t-1}, a g e_{i t-1}^{2},\right.} \\
& \left.e d u c_{i}, e d u c_{i}^{2}, e d u c_{i} \times a g e_{i t-1}\right] .
\end{aligned}
$$

The estimation results are displayed in Table 3. In the first column, we present results where we assume that the rate of depreciation $\sigma(t)$ is time constant. In the second column, we add a lagged interaction term of age and the health stock variable, thus allowing for an increase in the depreciation rate of health capital over the life cycle.

The wage effects are very similar in both specifications, and they reflect our previous findings. The estimated coefficient is negative, and significant at the 10 percent level. The interpretation of this coefficient is the same as in the above models: It is a scaled evolutionary wage effect on health investment. The estimate is slightly larger than the estimate obtained from the previous model.

\footnotetext{
${ }^{16}$ As the error process in the quasi-differenced equation displays an MA(2) structure we use $e^{H D_{i t-3}}$ and further lags as instruments.
} 
Table 3: Results for quasi-differenced multiplicative model for Health

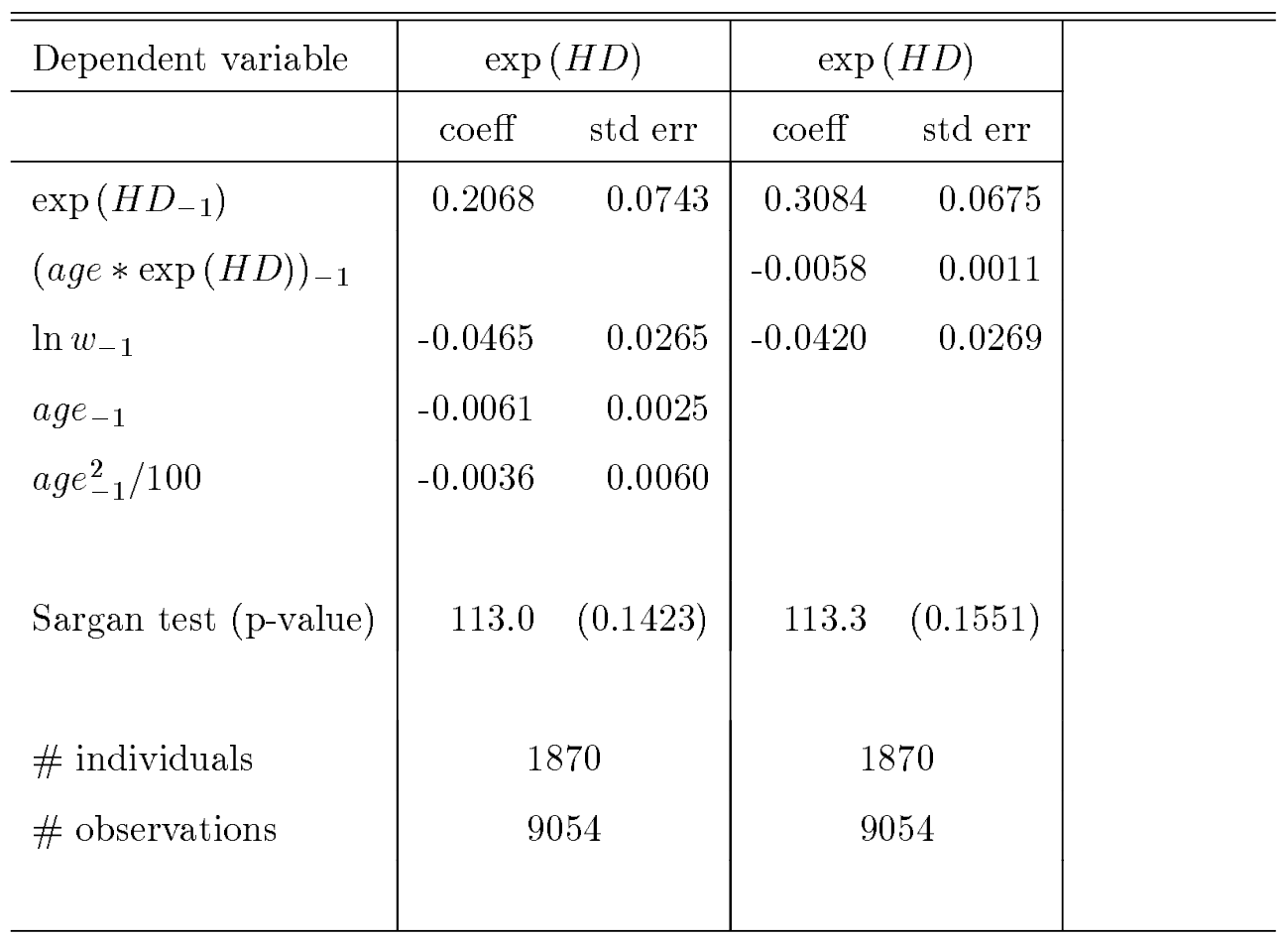

Efficient, iterated GMM results for quasi-differenced model.

Standard errors are robust to heteroscedasticity and correlation over time.

The Sargan test is a test for instrument validity.

The parameter on the lagged health stock variable corresponds to $(1-\sigma)$ in our theoretical model, where $\sigma$ is the rate of depreciation. Estimation of the simple level model (where we instrument $\exp \left(H_{i t-1}\right)$ by $\exp \left(H_{i t-2}\right)$ due to an MA(1) error process) gives an estimate for $\sigma$ of a magnitude of 0.078 (standard error 0.014). When we control for fixed effects (column 1 in Table 3), the estimate becomes unreasonably large, and the standard error increases. After controlling for the permanent effect, it seems difficult to identify $\sigma$ separately. ${ }^{17}$ In the second column, we allow for an increasing rate of health depreciation. Our formulation corresponds to an additively linear depreciation rate of the form $\sigma(t)=\sigma_{0}+\sigma_{1} *$ Age $(t)$. The parameter estimate

\footnotetext{
${ }^{17} \mathrm{~A}$ possible reason is the persistence in the health variable over time. It is therefore likely that our instruments are poor predictors of the quasi-differenced health variable, which could lead to a downward weak instrument bias (see Blundell and Bond (1998)).
} 
for $\sigma_{1}$ is negative, which is in accordance with our model.

\subsection{Permanent Wage Effects}

To recover the response in health or health investment to permanent shifts in wages, we need to impose structure on the individual specific effects. We use a parameterisation similar to MaCurdy (1981) and Blundell and MaCurdy (1999).

Suppose that $\ln \eta_{i}^{0}$ is a function of initial wealth $A^{0}$, initial health $H^{0}$, and the entire lifetime wage path:

$$
\ln \eta_{i}^{0}=\alpha_{0} A_{i}^{0}+\gamma_{0} H_{i}^{0}+\sum_{s=0}^{T_{W}} \theta_{s} \ln w_{i s}+v_{i}
$$

where the working life of the individual has length $T_{W}$, and $v_{i}$ is an idiosyncratic error term.

Specify individual $i$ 's wage in period $t$ as

$$
\ln w_{i t}=\pi_{0 i}+a g e_{i t} \pi_{1 i}+a g e_{i t}^{2} \pi_{2 i}+u_{i t},
$$

where the $\pi_{j i}, j=0,1,2$, are individual-specific lifetime wage parameters. Similarly, $i$ 's nonwage income in period $t\left(A_{i t}\right)$ and health are specified as

$$
\begin{aligned}
& A_{i t}=\tau_{0 i}+a g e_{i t} \tau_{1 i}+a g e_{i t}^{2} \tau_{2 i}+v_{i t}, \\
& H_{i t}=\omega_{0 i}+a g e_{i t} \omega_{1 i}+a g e_{i t}^{2} \omega_{2 i}+s_{i t},
\end{aligned}
$$

where $\tau_{0 i}$ and $\omega_{0 i}$ correspond to the initial stocks of resources and health respectively, and the $\tau_{j i}$ and $\omega_{j i}, j=1,2$, are individual-specific lifetime wealth and health parameters.

Combining (22), (23) and (24), $\ln \eta_{i}^{0}$ can be written as

$$
\ln \eta_{i}^{\mathbf{0}}=\alpha_{1}+\pi_{\mathbf{0} i} \bar{\theta}_{\mathbf{0}}+\pi_{1 i} \bar{\theta}_{1}+\pi_{2 i} \bar{\theta}_{2}+\tau_{\mathbf{0} i} \bar{\alpha}_{\mathbf{0}}+\omega_{\mathbf{0} i} \bar{\gamma}_{\mathbf{0}}+\varepsilon_{i}
$$

where

$$
\bar{\theta}_{j}=\sum_{t=\mathbf{0}}^{T_{W}} t^{j} \theta_{t}, \quad j=0,1,2, \quad \bar{\alpha}_{\mathbf{0}}=\frac{\alpha_{\mathbf{0}}}{r}, \quad \bar{\gamma}_{\mathbf{0}}=\frac{\gamma_{0}}{r+\sigma} .
$$


We obtain unbiased estimates of $\pi_{0}, \pi_{1 i}, \pi_{2 i}, \tau_{0 i}$ and $\omega_{0 i}$, following the procedure outlined by MaCurdy (1981). ${ }^{18}$ For the construction of the individual specific initial wealth parameter $\tau_{0}$, we use as a measure for non-wage income, $A_{i t}$, observed real total household income, excluding the earnings of the individual male. ${ }^{19}$ To recover the parameter $\omega_{i \mathbf{0}}$, we use the self reported health measure. Estimates of $\pi_{\mathbf{0} i}, \pi_{1 i}, \pi_{2 i}$, $\tau_{\mathbf{0}}$, and $\omega_{i \mathbf{0}}$ are based on the longest available series on log wages, household income, and health respectively.

From the estimation results of the differenced models the individual specific effects can be estimated by

$$
\widehat{\ln \eta_{i}^{0}}=\frac{1}{T_{i}} \sum_{t=1}^{T_{i}}\left[Y D_{i t}-\widehat{\zeta} \ln w_{i t}-a g e_{i t} \overline{\widehat{\delta}}_{\mathbf{0}}-a g e_{i t}^{2} \widehat{\delta}\right],
$$

with $\overline{\widehat{\delta}}_{\mathbf{0}}$ equal to the average of the $\widehat{\delta}_{0 t}$. For the dynamic equation, we obtain an estimate of $\ln \eta_{i}^{0}$ as

$$
\widehat{\ln \eta_{i}^{0}}=\ln \left(\frac{1}{T_{i}-1} \sum_{t=2}^{T_{i}} \frac{\exp \left(H D_{i t}\right)-\widehat{\alpha} \exp \left(H D_{i t-1}\right)}{\exp \left(\widehat{\zeta} \ln w_{i t-1}+a g e_{i t} \widehat{\delta}_{\mathbf{0}}+a g e_{i t}^{2} \widehat{\delta}\right)}\right)
$$

Using $\widehat{\ln \eta_{i}^{0}}, \hat{\pi}_{0 i}, \hat{\pi}_{1 i}, \hat{\pi}_{2 i}, \hat{\tau}_{\mathbf{0} i}$ and $\hat{\omega}_{\mathbf{0} i}$ we estimate equation (25) to obtain estimates of $\alpha_{1}, \bar{\theta}_{\mathbf{0}}, \bar{\theta}_{1}, \bar{\theta}_{2}$ and $\bar{\alpha}_{\mathbf{0}}$, using IV (since the explanatory variables are by construction

${ }^{18}$ The unbiased estimators of the $\pi$ 's are given by

$$
\begin{gathered}
\widehat{\pi}_{2 i}=\frac{1}{T_{i}-2} \sum_{j=1}^{T_{i}-2} \frac{1}{j}\left[\frac{\ln w_{i j+2}-\ln w_{i 1}}{j+1}-\left(\ln w_{i 2}-\ln w_{i 1}\right)\right] \\
\widehat{\pi}_{1 i}=\frac{1}{T_{i}-1} \sum_{j=1}^{T_{i}-1}\left[\frac{\ln w_{i j+1}-\ln w_{i 1}}{j}-\widehat{\pi}_{2 i}\left(2 a g e_{i j+1}-j\right)\right] \\
\widehat{\pi}_{0 i}=\frac{1}{T_{i}} \sum_{j=1}^{T_{i}}\left[\ln w_{i j}-\widehat{\pi}_{1 i} a g e_{i j}-\widehat{\pi}_{2 i} a g e_{i j}^{2}\right]
\end{gathered}
$$

where $j$ denote observed sample periods, and $\ln w_{i j}$ are $\log$ wages of individual $i$ in period $j$. The $\tau$ 's and $\omega$ 's are computed in a similar manner, with residual total household income and health status substituted for $\log$ wages.

${ }^{19}$ We have also estimated the models using different measures of non wage income. The results were very similar to those presented below. 
correlated with the error term). Our vector of instruments is given by

$$
z_{i}=\left[1, e d u c_{i}, e d u c_{i}^{2}, \text { feduc }_{i}, \text { meduc }_{i}, \text { agefb }_{i}, \text { agemb }_{i}, \text { fbluec }_{i}, \text { fwhitec }_{i}, \text { fcivserv }_{i}\right]
$$

where $f(m) e d u c$ is the number of years of schooling of the father (mother), age $f(m) b$ is the age of the father (mother) at birth, and fbluec, fwhitec and fcivserv indicate whether the father was/is occupying a blue-collar job, a white-collar job, or a civil servant job respectively.

Table 4: Estimation results for permanent effects model

\begin{tabular}{|c|c|c|c|c|c|c|}
\hline & \multicolumn{2}{|c|}{ Health } & \multicolumn{2}{|c|}{$\begin{array}{c}\text { Health } \\
\text { (Dynamic Model) }\end{array}$} & \multicolumn{2}{|c|}{ Health Investment } \\
\hline & coeff & std err & coeff & std err & coeff & std err \\
\hline const & 0.7819 & 0.1689 & 0.5785 & 0.2538 & 0.1959 & 0.3297 \\
\hline $\bar{\theta}_{0}$ & 0.0590 & 0.0615 & 0.0634 & 0.0970 & 0.1483 & 0.1225 \\
\hline $\bar{\theta}_{1}$ & 1.0435 & 1.0180 & 1.2074 & 1.6226 & 2.9034 & 2.0005 \\
\hline $\bar{\theta}_{2}$ & 13.8553 & 13.0137 & 16.7098 & 20.0566 & 36.1682 & 23.7592 \\
\hline $\bar{\alpha}_{0}$ & -0.0007 & 0.0007 & -0.0008 & 0.0010 & 0.0002 & 0.0015 \\
\hline $\bar{\gamma}_{0}$ & 0.0022 & 0.0034 & 0.0024 & 0.0043 & 0.0021 & 0.0068 \\
\hline Sargan test (p-value) & 0.415 & 0.981 & 0.352 & 0.986 & 1.926 & 0.749 \\
\hline Wald test (p-value) & 1.291 & 0.721 & 1.618 & 0.655 & 8.446 & 0.038 \\
\hline \# of individuals & \multicolumn{2}{|c|}{1420} & \multicolumn{2}{|c|}{1415} & \multicolumn{2}{|c|}{1370} \\
\hline
\end{tabular}

Efficient two-step GMM results.

Standard errors are robust to heteroscedasticity.

The Sargan test is a test for instrument validity.

The Wald test is a test for joint significance of $\bar{\theta}_{\mathbf{0}}, \overline{\theta_{1}}$ and $\overline{\theta_{2}}$.

The estimation results are presented in Table 4. The coefficient on initial wealth $\left(\bar{\alpha}_{0}\right)$ is negative in the health equation and positive in the health investment equation. For both equations, the estimates of the coefficient on initial health $\left(\bar{\gamma}_{\mathbf{0}}\right)$ is positive. 
Also, for both equations, $\bar{\theta}_{0}, \bar{\theta}_{1}$, and $\bar{\theta}_{2}$ are positive, indicating positive permanent wage effects. All these effects are however not precisely estimated. The joint test of significance for the permanent wage parameters is significant for the health investment equation.

The overall response to a change in wages can be obtained by combining the estimation results for $\zeta, \bar{\theta}_{\mathbf{0}}, \bar{\theta}_{1}$, and $\bar{\theta}_{2}$. For example, a change in $\pi_{\mathbf{0}}$ would correspond to a permanent parallel shift in the log wage profile, as, for instance, a shift from $B$ to $B^{\prime}$ in figure 1. As we have discussed above, such a hypothetical shift creates a permanent response, and an evolutionary response. For the (non-dynamic) health equation the permanent response is given by $\frac{\partial \eta_{0}}{\partial \pi_{0}}=\bar{\theta}_{0}=0.0590$. The evolutionary response is given by $\zeta=-0.0163$.

The total response to this shift is given by combining the permanent response across two individuals, and the evolutionary response. For the (non-dynamic) health equation, this parameter is $\frac{\partial H D}{\partial \pi_{0}}=0.0590-0.0163=0.0427$. For the health investment equation, the total effect is given by $\frac{\partial I D}{\partial \pi_{0}}=0.1483-0.0308=0.1075$. These estimates seem to suggest that evolutionary responses are relatively small, as compared to permanent responses. Notice however that here we shift the entire wage profile. But a one percent increase in wages at one point in time would not lead to a one percent increase in permanent wages. Accordingly, at stages in the life cycle where wages grow very rapidly, the negative evolutionary response may lead to serious drops in health and health investments.

To illustrate this, we have simulated an individual who's wage profile is the average wage profile of the sample, as depicted in figure 3. For this individual we can estimate $\pi_{0}, \pi_{1}$ and $\pi_{2}$. We use the estimated parameters for the (non-dynamic) health equation and obtain an estimate of $\ln \eta_{0}$ (where we assume that initial health and wealth are zero).

Now consider a second individual, with exactly the same wage profile, except that he has $10 \%$ higher wages for 4 years between the ages $40-43$. Consequently, for this 
individual the estimate for $\ln \eta_{0}$ is slightly larger (by 0.04\%), and this individual is on a higher permanent health path. However, during the 4 years of higher wages, his health stock is lower, due to the dominating evolutionary component. Using our estimates, the (negative) evolutionary response to this increase between the ages $40-43$ is 18 times larger than the permanent response.

As a comparisson, we have also estimated standard cross section models on pooled data, where we condition on age, age squared, education, and time dummies. The estimated wage coefficient for the health equation is 0.044 , with standard error 0.011 ; in the health investments equation, the coefficient on wages is 0.125 , with a standard error of 0.029 . We have also estimated a cross section model of the dynamic health equation, where we do not control for $\eta_{i}^{0}$. The parameter estimate of the wage coefficient is 0.0433 (standard error 0.0124). All these coefficients suggest a positive relationship between wages and health. They are compound effects of evolutionary, and weighted permanent wage responses. As we have illustrated in section (2.2), they do not correspond to any of the parameters of interest, and may wrongly identify individuals to be in need of possible health support. Conclusions based on these results would suggest that there is no difference between the health stocks of the two individuals in our above example, except for the 4 years of higher wages of the second individual, where the health stock of the second individual is larger. This is clearly in contrast to the conclusions we draw from our life cycle analysis.

\subsection{Instantaneous Benefits of Health}

So far we have assumed that there are no instantaneous health benefits: $h^{\prime}=0$. A simple test of this assumption is based on the following idea. Recall equation (13), and define $D(t)=e^{\int_{0}^{t}[\sigma(\tau)+r] d \tau}$. Then the first difference of the log of $\eta(t)$ can be written as

$$
\begin{aligned}
\ln \eta(t)-\ln \eta(t-1)= & \ln D(t)-\ln D(t-1) \\
& +\ln \left(1-\frac{E(t)+F(t)}{\ln D(t) \eta(0)}\right)-\ln \left(1-\frac{E(t-1)+F(t-1)}{D(t-1) \eta(0)}\right)
\end{aligned}
$$




$$
=\ln D(t)-D(t-1)+\Gamma(t) .
$$

If health has an instantaneous benefit $\left(h^{\prime} \neq 0\right)$, then straightforward differencing, or quasi-differencing, does not eliminate the permanent effect. The residual in the first differenced model will contain the term $\Gamma(t)$, which is a function of $\eta(0), \lambda_{1}(0)$, and past wages. Hence, a test whether $h^{\prime}=0$ is a test for the validity of lagged wages as instruments in our model above.

An appropriate test is the Sargan test for overidentifying restrictions. We present the test statistics and the p-values of this test in Tables 2 and 3. The p-values strongly indicate that the errors are not correlated with the instruments, for both the health and the health investment equations. We conclude from these results that the simple model where health has no instantaneous benefit can not be rejected against a model where the stock of health has a time enhancing effect.

To check the robustness of our results, we use an alternative estimation strategy which allows us to identify the evolutionary wage effects if there are instantaneous benefits $\left(h^{\prime} \neq 0\right)$. The parameter $\eta$ is a function of variables that are correlated with the regressors. Individuals who have similar values of those variables will also be similar in the correlated component of $\eta$. Hence, differencing across individuals with the same values of these variables should eliminate the variation in $\eta$ which is correlated with wages.

This estimator is a matching estimator. It is consistent as long as the remaining error term in the differenced equation is no longer correlated with wages. Note that, for obtaining a consistent estimate of the evolutionary wage response, up to scale, it is not necessary that the matching procedure completely determines $\eta$.

We illustrate this estimator for the log-linear specifications (12) and (16). ${ }^{20}$ The parameter $\eta_{i t}$ is a function of life cycle wages, life cycle wealth, and initial wealth and health conditions. To implement the estimator, we match observations exactly on age

\footnotetext{
${ }^{20}$ See also the discussion in section (2.2) for a graphical explanation of the matching estimator.
} 
and education, and on kernel weighted distances between predicted life cycle wages and life-cycle wealth, the individual specific sample means of these variables, and on initial wealth and health. All these variables are constructed in the same way as for the estimation of the permanent effects in the previous section. We then estimate pair-wise differenced equations between individuals.

Our matching estimator is similar to the estimation strategy explained in Kyriazidou (1997) for sample selection panel data models and is given by

$$
\widehat{\zeta}^{M}=\left[\sum_{j=1}^{J} \sum_{k=1}^{K_{j}} \sum_{l>k} \psi_{j N}\left(x_{j k}-x_{j l}\right)\left(x_{j k}-x_{j l}\right)^{\prime}\right]^{-1} \sum_{j=1}^{J} \sum_{k=1}^{K_{j}} \sum_{l>k} \psi_{j N}\left(x_{j k}-x_{j l}\right)\left(y d_{j k}-y d_{j l}\right)^{\prime}
$$

where $J$ is the number of groups of individuals with the same age and years of education, with each group containing $K_{j}$ observations. The $x_{j k}$ and $x_{j l}$ are the observations on the explanatory variables, in our case wages and time effects, for individuals $k$ and $l$ in age-education group $j$ respectively. The kernel weights $\psi_{j N}$ decline to zero as the magnitude of the difference between the matching variables increases. These weights are specified as

$$
\psi_{j N}=\prod_{q=1}^{Q} \frac{1}{h_{N q}} \phi\left(\frac{z_{j k}^{q}-z_{j l}^{q}}{h_{N q}}\right),
$$

where $Q$ is the number of (standardised) matching variables $z^{q}, h_{N q}$ is a sequence of bandwidths that tend to zero as the number of individuals goes to infinity $(N \rightarrow$ $\infty$ ), and $\phi$ is the standard normal density function. For the choice of the bandwidth parameter, we follow Kyriazidou (1997), and set the bandwidth $h_{N q}=h_{q} \times N^{-1 / 5}$, where $h_{q}=1$ for the predicted life cycle wages and life-cycle wealth and their individual specific means, and $h_{q}=2$ for initial wealth and health, because of the slightly fatter tails of the distributions of these two variables, and hence ensuring sufficient data coverage.

The estimates of the coefficient on $\ln w$ are -0.0185 (standard error 0.0111) in the equation for $H D$ and -0.0353 (standard error 0.0495 ) in the equation for $I D$. These estimates are remarkably similar to the ones found for the differenced models, as reported in Table 2. This supports our previous findings, suggesting that there are 
negative responses of health investments to transitory wage changes. Furthermore, together with the test results, the similarity between the sets of estimates indicate that instantaneous health benefits do not affect estimates of evolutionary wage responses.

\section{Conclusion and Discussion}

In this paper, we present a life cycle model for health demand, and derive and estimate Frisch demand functions for health and health investment. In our model, changes in wages induce a permanent and an evolutionary wage response of health (or health investment). We suggest two estimation strategies which allow us to distinguish between permanent and evolutionary responses. The first strategy relies on differencing procedures. Our second estimation strategy relies on a matching type estimator, which allows us to identify transitory wage effects if simple differencing does not eliminate the latent individual effect. This is the case if health provides instantaneous benefits, since simple differencing does not eliminate the variation in the latent individual effect which is correlated with the model regressors. We also propose a simple test for the restricted model against a model where health does provide instantaneous benefits.

We use data on contentment with health and the demand for sport activities from a long panel. In accordance with the theoretical model, we find negative evolutionary wage effects, indicating that individuals substitute time for health production for time in the labour market during high wage periods over their life cycle. Furthermore, we find positive permanent effects, indicating that individuals with higher permanent wages are on a higher health profile. These results are in contrast to what we obtain when estimating a simple cross section model. In our cross section models, contemporaneous wages are strongly and positively associated with health and health investments.

Estimates obtained from a simple cross section analysis suggest therefore that individuals with low wages suffer from poorer health conditions, and have lower health investments. An implication for health policies is to target individuals in the lower 
quantiles of the wage distribution. In contrast, our model suggests that the intertemporal dimension is important for assessing issues relating health and wages. In fact, the current wage situation of an individual may be a poor indicator for health investments and health status.

Individuals with higher life cycle wages may be on a higher health (and health investment) profile, although they may (temporarily) have low wages. Conclusions based on a simple cross section analysis may wrongly identify temporarily poor individuals as being in need of health support.

On the other side, our model identifies high wage individuals as being possibly threatened by health risks. At peak periods of their individual wage profiles, individuals may tend to substitute time away from health enhancing activities to the work place. Our model is compatible with observations in the medical literature that individuals in the highest occupational groups suffer from serious illness (see Marmot et al., 1997). Simulations based on our model estimates suggest that responses to evolutionary wage increases may indeed be detrimental to health and health investment. Our analysis emphasises the need to consider health related behaviour in a truly intertemporal context. Any examination of the connections between wages and health will need to address the issues raised in this paper. 


\section{References}

[1] Arellano, M. and S. Bond (1991) Some Tests of Specification for Panel Data: Monte Carlo Evidence and an Application to Employment Equations, Review of Economic Studies, 58, 277-298.

[2] Arellano, M. and S. Bond (1998) Dynamic Panel Data Estimation using DPD98 for Gauss, manual, The Institute for fiscal Studies.

[3] Blundell, R. and S. Bond (1998) Initial Conditions and Moment Restrictions in Dynamic Panel Data Models, Journal of Econometrics, 87, 115-143.

[4] Blundell, R., R. Griffith and F. Windmeijer (1999) Individual Effects and Dynamics in Count Data Models, Working Paper No. W99/3, The Institute for Fiscal Studies.

[5] Blundell, R. and T. MaCurdy (1999) Labor Supply: A Review of Alternative Approaches, in: O. Ashenfelter and D. Card (eds.), Handbook of Labor Economics, Volume III, North-Holland, Amsterdam.

[6] Browning, M., Deaton, A. and M. Irish (1985) A Profitable Approach to Labour Supply and Commodity Demand over the Life Cycle, Econometrica, 53, 503 - 543.

[7] Chamberlain, G. (1992) 'Comment: Sequential Moment Restrictions in Panel Data', Journal of Business 6 Economic Statistics, 10, 20-26.

[8] Chung, C.-F. and A.S. Goldberger (1984) Proportional Projections in Limited Dependent Variable Models, Econometrica, 52, 531-534.

[9] Cropper, M.L. (1981) Measuring the Benefits from Reduced Morbidity, American Economic Review, 71, 235-240.

[10] Dardanoni, V. and A. Wagstaff (1990) Uncertainty and the Demand for Medical Care, Journal of Health Economics, 9, $23-38$. 
[11] Eisenring, C. (1999) Comparative Dynamics in a Health Investment Model, Journal of Health Economics, 18, 655-660.

[12] Ehrlich, I. and H. Chuma (1990) A Model of the Demand for Longevity and the Value of Life Extension, Journal of Political Economy, 98, 761-782.

[13] Geil, P., A. Million, R. Rotte and K.F. Zimmermann (1997) Economic Incentives and Hospitalization in Germany, Journal of Applied Econometrics, 12, 295-312.

[14] Grossman, M. (1972a) The Demand for Health: A Theoretical and Empirical Investigation, NBER, New York.

[15] Grossman, M. (1972b) On the Concept of Health Capital and the Demand for Health, Journal of Political Economy, 80, 223-255.

[16] Grossman, M. (1998) On Optimal Length of Life, Journal of Health Economics, 17, 499-509.

[17] Hansen, L.P. (1982) 'Large Sample Properties of Generalized Method of Moments Estimators', Econometrica, 50, 1029-1054.

[18] Heckman, J., H. Ichimura and P. Todd (1998) Matching as an Econometric Evaluation Estimator, Review of Economic Studies, 65, 605-654.

[19] Heckman, J. and T. MaCurdy (1980) A Life-Cycle Model of Female Labor Supply, Review of Economic Studies, 47, 47-74.

[20] Kyriazidou, E. (1997) Estimation of a Panel Data Sample Selection Model, Econometrica, 65, 1335-1364.

[21] Lee C. D., S. N. Blair and A. S. Jackson (1999) Cardiorespiratory Fitness, Body Composition, and All-Cause and Cardiovascular Disease Mortality in Men, The American Journal of Clinical Nutrition, 69, 373-380. 
[22] Liljas, B. (1998) The Demand for Health with Uncertainty and Insurance, Journal of Health Economics, 17, 153-171.

[23] MaCurdy, T.E. (1981) An Empirical Model of Labor Supply in a Life-Cycle Setting, Journal of Political Economy, 89, 1059-1086.

[24] Marmot, M., C. D. Ryff, L. L. Bumpass, M. Shipley and N. F . Marks (1997) Social Inequalities in Health: Next Questions and Converging Evidence, Social Science 89 Medicine, 44, 901-910.

[25] Muurinen, J.M. (1982) Demand for Health: A Generalized Grossman Model, Journal of Health Economics, 1, 5-28.

[26] Newey, W.K. (1986) Linear Instrumental Variable Estimation of limited Dependent Variable Models with Endogenous Explanatory Variables, Journal of Econometrics, 32, 127-141.

[27] Picone, G., Uribe, M. and R. M. Wilson (1998) The Effect of Uncertainty on the Demand for Medical Care, Health Capital, and Wealth, Journal of Health Economics, 17, 153-171.

[28] Pohlmeier, W. and V. Ulrich (1995) An Econometric Model of the Two-Part Decision-making Process in the Demand for Health Care, Journal of Human Resources, 30, 339-361.

[29] Ried, W. (1998) Comparative Dynamic Analysis of the Full Grossman Model, Journal of Health Economics, 17, 383-425.

[30] Ried, W. (1999) Optimal Length of Life: Another Perspective, Journal of Health Economics, forthcoming.

[31] Rosenbaum, P. and D. Rubin (1983) The Central Role of the Propensity Score in Observational Studies for Causal Effects, Biometrika, 70, 41-55. 
[32] Ruud, P.A. (1986), Consistent Estimation of Limited Dependent Variable Models despite Misspecification of Distribution, Journal of Econometrics, 32, 157-187.

[33] Wagstaff, A. (1986) The Demand for Health: Some New Empirical Evidence," Journal of Health Economics, 5, 195-233.

[34] Wagstaff, A. (1993) The Demand for Health: An Empirical Reformulation of the Grossman Model, Health Economics, 2, 189-198.

[35] Wannamethee, G. and A.G. Shaper (1991) Self-assessment of Health Status and Mortality in Middle-Aged British Men, International Journal of Epidemiology, 20, 239-245.

[36] Wooldridge, J.M. (1997) 'Multiplicative Panel Data Models without the Strict Exogeneity Assumption', Econometric Theory, 13, 667-678. 


\section{Appendix A}

\section{Solving the model}

The Hamiltonian is given by equation (10) above. Using Pontryagin's maximum principle, the optimal paths of the variables $I(t), C(t), \lambda_{1}(t), \lambda_{2}(t), H(t)$ and $A(t)$ as well as $T$ are determined by equations (1) and (7) and the following system of equations:

$$
\begin{array}{rll}
\frac{d K}{d c} \quad & : \quad e^{-\rho t} u_{c}-\lambda_{1}(t) p_{c}=0 \\
\frac{d K}{d I} \quad: \quad & \lambda_{2}-\lambda_{1} \pi\left(\frac{1}{a+b}\right) I(t)^{\frac{1}{a+b}-1}=0 \\
-\frac{d K}{d H}=\dot{\lambda}_{2} \quad: \quad & \dot{\lambda}_{2}(t)=\lambda_{2}(t) \sigma(t)-\lambda_{1}(t) w(t) h^{\prime}-e^{-\rho t} v_{h} h^{\prime} \\
-\frac{d K}{d A}=\dot{\lambda}_{1} \quad: \quad & \dot{\lambda}_{1}=-\lambda_{1} r .
\end{array}
$$

The transversality conditions are given by:

$$
\begin{aligned}
\lambda_{1}(T)(A(T)-\bar{A}) & =0, \\
\lambda_{2}(T)\left(H(T)-H_{c}\right) & =0 .
\end{aligned}
$$

The termination condition becomes:

$$
u(c(T)) e^{-\rho T}+\lambda_{1}(T) \dot{A}(T)+\lambda_{2}(T) \dot{H}(T)=0 .
$$

For sufficiency, we need that $\lambda_{1}(t) \geq 0 \forall t$. Ehrlich and Chuma (1990) show that the length of life is finite if three conditions are fulfilled: health depreciation increases with age, the critical minimum health level is positive, and the maximum debt is limited to the finite magnitude of human wealth. We assume that these conditions are fulfilled.

Define the shadow price of health capital as $\eta(t)=\frac{\lambda_{2}(t)}{\lambda_{1}(t)}$. Then it follows from the first order conditions that:

$$
\eta(t)\left[\sigma(t)+r-\frac{\dot{\eta}(t)}{\eta(t)}\right]=w(t) h^{\prime}-e^{(r-\rho) t} v_{h} \frac{1}{\lambda_{1}(0)} h^{\prime},
$$

where $h^{\prime}$ denotes the derivative of $h$ with respect to $H(t)$. Equation (34) is the equilibrium condition for investment in health capital. The left hand side corresponds to the marginal 
cost of changing the stock of health capital, while the right hand side is the instantaneous marginal benefit.

Solving equation (34) results in equation (13) above. The parameter $\eta(0)$ is the shadow value of health at time 0 . It is a function of the lifetime profile of earnings, prices, tastes, and the rates of interest, impatience, and depreciation. It is determined simultaneously with the optimal longevity $T$, and the marginal utility of wealth $\lambda_{1}(0)$ by the following system of equations:

$$
\begin{aligned}
& H(T)=e^{-\int_{0}^{T} \sigma(\tau) d \tau}\left[H(0)+\int_{0}^{T} I(s) e^{\int_{0}^{s} \sigma(\tau) d \tau} d s\right]=H^{C} \\
& A(T)=\int_{0}^{T}\left[w(\tau) h(\tau)-\pi(\tau) I(\tau)^{\frac{1}{a+b}}-p_{c} c(\tau)\right] e^{r(T-\tau)} d \tau+e^{r T} A(0)=\bar{A},
\end{aligned}
$$

and

$$
\begin{aligned}
& \frac{1}{\lambda_{1}(0)}[u(c(T))+v(h(T))] e^{(r-\rho) T} \\
& \quad+\left[r A(T)-\pi I(T)-p_{c} c(T)+w(T) h(T)\right] \\
& +\eta(T)[I(T)-\sigma(T) H(T)]=0
\end{aligned}
$$

With decreasing returns to scale, the demand for health investments is given by:

$$
I(t)=\left[\frac{\eta(t)(a+b)}{\pi\left(p_{M}, w(t), \phi(t)\right)}\right]^{\frac{a+b}{1-a-b}}
$$

Equation (38) follows directly from the derivative of the Hamilton function with respect to investment. Investment $I(t)$ increases in $\eta(t)$, and decreases in $\pi(t)$.

Combining (38) and (4) yields the demand for health services $M(t)$ :

$$
M(t)=B \phi^{\frac{1}{1-a-b}} p_{M}^{-\frac{1-b}{1-a-b}} w(t)^{-\frac{b}{1-a-b}} \eta(t)^{\frac{1}{1-a-b}} .
$$


Appendix B: The Questionnaire

The question on contentment with health is stated as

How content are you with your heath status? Answers are possible on an 11 point scale, ranging from entirely uncontent to entirely content.

The question on sport activities is available for the years $85,86,88,92$, and 94 . There were also respective questions in 84 and 95 , but the coding was different, and not compatible with the questions in the remaining years. We therefore exclude these years.

The wording of the questions is

Which of the following activities do you pursue in your leisure time? Please state how often you engage in this activity.

Possible answers for the category Active Sport are: each week, each month, rarely ever, never. The variable we constructed from this information assumes the value 1 if the individual classifies into the category each week. 